\title{
Bulanık Mantık Tabanlı Bir Hibrit Yol Takip Yöntemi
}

\author{
Muhammed Çelik ${ }^{1 *}$, Cenk Ulu $^{2}$ \\ ${ }^{1}$ Yıldız Teknik Üniversitesi, Makine Fakültesi, Mekatronik Mühendisliği Bölümü, İstanbul, Türkiye (ORCID: 0000-0001-6909-7830) \\ ${ }^{2}$ Yıldız Teknik Üniversitesi, Makine Fakültesi, Mekatronik Mühendisliği Bölümü, İstanbul, Türkiye (ORCID: 0000-0002-8588-6247)
}

(International Congress on Human-Computer Interaction, Optimization and Robotic Applications (HORA) 2021 - 11-13 June 2021)

(DOI: $10.31590 /$ ejosat.944108)

ATIF/REFERENCE: Çelik, M. \& Ulu, C. (2020). Bulanık Mantık Tabanlı Bir Hibrit Yol Takip Yöntemi. Avrupa Bilim ve Teknoloji Dergisi, (26), 301-306.

\begin{abstract}
Özet
Literatürde otonom kara araçları yol takibi problemini çözmek için farklı yöntemler önerilmiştir. Bu yöntemler geometrik tabanlı ve model tabanlı yöntemler olarak iki ana gruba ayrılabilir. Model tabanlı yöntemlerde aracın dinamik modeli kullanılırken, geometrik tabanlı yöntemlerde sadece araç ve yol arasındaki geometrik ilişkilerden yararlanılır. Yapılarının basit olması nedeniyle geometrik tabanlı yöntemler uygulamalarda sıklıkla kullanılmaktadır. Stanley ve Pure Pursuit yöntemleri en yaygın kullanılan geometrik tabanlı yöntemlerdir. Stanley yöntemi düz yolda daha iyi bir yol takip performansı gösterirken, dönüşlerde daha düşük bir performans sergilemektedir. Pure Pursuit yöntemi ise dönüşlerde daha iyi bir performans sergilerken, düz yolda daha düşük bir performans göstermektedir. Bu çalışmada Pure Pursuit ve Stanley yöntemlerinin üstün yanlarını bir arada kullanabilmek için bulanık mantık tabanlı bir hibrit kontrol yöntemi önerilmiştir. Bu yöntemde yolun geometrisine bağlı olarak Stanley ve Pure Pursuit yöntemleri ile elde edilen direksiyon açı değerleri ağırlıklandırılarak tek bir direksiyon açısı değeri hesaplanmaktadır. Ağırlıklandırma parametresi dinamik olup bir bulanık çıkarım mekanizması tarafından ileri bakma açısı değerlendirilerek ayarlanmaktadır. Önerilen yöntemin performansı farklı yol şartlarında test edilmiş ve elde edilen sonuçlar Stanley, Pure Pursuit yöntemleri ve mevcut bir hibrit yöntem ile karşılaştırılmıştır. Benzetim sonuçları önerilen yöntemin diğer klasik iki yönteme ve mevcut hibrit yönteme göre daha üstün bir yol takip performansı sergilediğini göstermiştir.
\end{abstract}

Anahtar Kelimeler: Yol takibi, otonom araçlar, geometrik yol takibi, hibrit kontrol, bulanık mantık.

\section{A Fuzzy Logic Based Hybrid Path Tracking Method}

\begin{abstract}
Various methods have been proposed to solve the path tracking problem of autonomous ground vehicles in the literature. These methods can be divided into two main groups as geometric-based and model-based methods. While the dynamic model of the vehicle is used in model-based methods, only geometric relations between the vehicle and the path are used in geometric-based methods. Geometric-based methods are frequently used in applications due to their simple structures. Stanley and Pure Pursuit methods are the most widely used geometric-based methods. While the Stanley method shows a better tracking performance on a straight path, it shows a lower performance on turns. On the other hand, the Pure Pursuit method performs better performance on turns but shows a lower performance on the straight paths. In this study, a fuzzy logic-based hybrid control method is proposed to use the advantages of Pure Pursuit and Stanley methods together. In this method, the steering angle value is calculated by weighting the steering angle values obtained by Stanley and Pure Pursuit methods depending on the geometry of the path. The weighting parameter is dynamic and is adjusted by a fuzzy inference mechanism by evaluating the look-ahead angle. The performance of the proposed method is tested under different path conditions and the results obtained are compared with Stanley, Pure Pursuit methods, and an existing hybrid method. The simulation results show that the proposed method exhibits a superior path tracking performance compared to the other two conventional methods and the existing hybrid method.
\end{abstract}

${ }^{*}$ Sorumlu Yazar: Yıldız Teknik Üniversitesi, Makine Fakültesi, Mekatronik Mühendisliği Bölümü, İstanbul, Türkiye, ORCID: 0000-0001-6909-

7830, muhammedcelik.d@gmail.com 
Keywords: Path tracking, autonomous vehicles, geometric path tracking, hybrid control, fuzzy logic.

\section{Giriş}

Otonom araçlar, üzerlerinde bulunan gelişmiş sensörler ve işlemciler sayesinde otonom olarak hareket etme kabiliyetine sahip araçlardır. Gelişen teknoloji ve talepler doğrultusunda otonom araçların yaygın olarak kullanılması için yapılan otonom sürüş çalışmaları da hız kazanmaktadır. Otonom sürüşteki temel amaç, araç donanımlarının bulunduğu çevreden almış olduğu bilgileri sahip olduğu karar mekanizması ve kontrol algoritmaları sayesinde değerlendirerek bir direksiyon açısı, gaz ve fren çıktılarını en uygun değerlerde ortaya koymaktır.

Amidi (Amidi ve Thorpe, 1991) başarılı bir otonom araç geliştirmek için birkaç problemin ele alınması ve ben neredeyim?, nereye gitmek istiyorum? ve kendime zarar vermeden hedefe nasıl gidebilirim? sorularına cevap verebilmesi gerektiğini belirtmiştir. $\mathrm{Bu}$ sorular göz önüne alındığında bir otonom aracın sahip olması gereken üç temel birim bulunmalıdır. Bunlar algılama ve işleme birimi, planlama birimi ve kontrol birimidir. Algılama ve işleme biriminin görevi sensörlerden gelen verileri işleyerek aracın gerçek zamanlı konumunu ve ortam bilgilerini sağlamaktır. Planlama biriminde aracın izleyeceği güvenli ve uygulanabilir yörünge planlaması gerçekleştirilmektedir. Kontrol birimi ise aracı istenilen yörüngede hareket ettirmek için gerekli kontrol stratejilerini içermektedir (Amer vd., 2017).

Otonom araçlar için geliştirilen yol takibi yöntemleri genel olarak geometrik tabanlı ve model tabanlı olmak üzere iki ana başlık altında incelenebilir. Geometrik tabanlı yol takibi yöntemlerinde araç ve yol arasındaki geometrik ilişkilerden yararlanılmaktadır. Basit yapıları ve görece etkili sonuçlar ortaya koymalarından dolayı geometrik yol takip yöntemleri birçok uygulamada tercih edilmektedirler. $\mathrm{Bu}$ yöntemler arasında en yaygın olarak kullanılanları Pure Pursuit, Stanley ve Vector Pursuit yöntemleridir (Park, Lee, ve Han, 2014).

Pure Pursuit yöntemi düşük hılarda iyi bir performans sergilemektedir. Fakat hız arttıkça keskin dönüşlerde çapraz yol hataları da artmaktdır. Literatürde bu çapraz yol hatasının azaltılmasına yönelik çeşitli yöntemler önerilmiştir (M. Park, Lee, ve Han, 2015; Cibooglu, Karapinar, ve Soylemez, 2017). Pure Pursuit kontrolör, Stanley kontrolöre nazaran değişen yol geometrilerine göre daha iyi bir performans sağlamaktadır (Park, Lee, ve Han, 2014). Bunun nedeni ise ileri bakma davranış1 sayesinde değişen yol geometrisine önceden uyum sağlayabilmesidir (Snider, 2009). Stanley kontrolör ise düz yolda daha üstün bir performans göstermektedir. Cibooğlu vd. (2017) daha üstün bir takip performansı elde etmek için Pure Pursuit ve Stanley yöntemlerinin birlikte kullanıldığı bir hibrit yöntem önermişlerdir. Bir diğer yöntem ise araç modeli ve ileri bakma davranışının bir arada kullanıldığı yöntemdir (Jalali, Lambert, ve McPhee, 2012). Bu yöntemde gerçek sürücü tepkileri de sisteme girdi olarak tanımlanır. Ayrıca ileriye bakma davranışı sayesinde yol öngörülebildiği için direksiyon açısı, gaz ve fren pedalı konumları da yol geometrisine göre ayarlanmaktadır.

Model tabanlı yol takip yöntemlerinde kinematik ve dinamik araç modelleri kullanılmaktadır. Kinematik modele nazaran dinamik model daha karmaşık ve uygulanması daha zordur. Model tabanlı kontrol yöntemlerinden en popüler olan yöntemlerden biri Model Öngörülü Kontrol yöntemidir (Guo vd., 2019; Raffo vd., 2009). Bu yöntem, araç için gerekli kontrol girdisini tahmin etmek için genellikle doğrusal veya doğrusal olmayan bir araç modeli kullanır.
$\mathrm{Bu}$ yöntemlerin yanı sira klasik kontrol yöntemlerinin kullanıldığı çalışmalar da vardır. Bu kontrolörler genellikle yörüngeye bağlı olarak hız ve direksiyon açısını kontrol etmek için kullanılırlar. Hoffman vd.(2007) yaptıkları çalışmada Stanley kontrolör kullanmışlardır. Bununla birlikte, çalışma ayrıca bir PI kontrolör ile aracın gaz ve fren girişini kontrol etmektedir. Park vd. (2015) üretilen direksiyon açısının çıkışını arzu edilen değere ulaşması için kontrolör çıkışını PID kontrolör ile denetleyerek daha kararlı bir kontrolör ortaya koymuşlardır. Ayrıca bazı bulanık mantık tabanlı kontrol yöntemleri de önerilmiştir. Ping vd. (2012) önerdikleri yöntemde çapraz yol hatasını PI kontrolör ile, sapma açısını ise bir bulanık mantık denetleyicisiyle kontrol etmişlerdir. Yu vd. (2020) bir bulanık mantık tabanlı Pure Pursuit önermişlerdir. Önerilen yöntemde referans arka akstan ön aksa taşınmış ve parametrelerin ayarlanması için bir bulanık denetleyici kullanılmıştır.

$\mathrm{Bu}$ çalışmada otonom araçların yol takip uygulamaları için bulanık mantık tabanlı bir hibrit kontrol yöntemi önerilmiştir. Yöntemde araca uygulanacak direksiyon açısı değeri Pure Pursuit ve Stanley kontrolörlerinin ürettiği direksiyon açısı değerlerinin ağırlıklandırılması ile hesaplanmaktadır. Yöntemde dinamik bir ağırlıklandırma parametresi kullanılmıştır. Bu ağırlıklandırma parametresinin değeri bir bulanık çıkarım mekanizması tarafindan ileri bakma açısı değerlendirilerek ayarlanmaktadır. Önerilen yöntemin performansını değerlendirmek üzere farklı yol şartları için benzetim çalışmaları gerçekleştirilmiştir. Elde edilen sonuçlar geleneksel Stanley ve Pure Pursuit yöntemleri ve literatürde önerilmiş bir hibrit yöntem ile karşılaştırılmıştır. Karşılaştırma sonuçları ile önerilen yöntemin diğer yol takip yöntemlerinden daha üstün bir performans sergilediğini gösterilmiştir.

Bu makale 5 bölümden oluşmaktadır. 2. bölümde kullanılan yöntemler ve 3. Bölümde ise önerilen yöntem ayrıntılı olarak açıklanmıştır. 4 . bölümde benzetim sonuçları ve 5 . bölümde ise sonuçlar verilmiştir.

\section{Yol Takip Yöntemleri}

\subsection{Pure Pursuit Yöntemi}

Geometrik yöntemler arasındaki en popüler yöntemlerden biridir. İlk defa 1990 yılında Coulter (1992) tarafından geliştirilmiştir. Yöntem, araç ve yol geometrisi arasındaki ilişkilerden yararlanılarak formüle edilir. Önceden tanımlanmış yolda aracın arka aks merkezinden referans alınarak sabit bir ileri bakma mesafesinde bir ileri bakma noktası belirlenir. Belirlenen bu nokta ile aracın arka aksının merkezini referans alan bir eğri oluşturulur. Oluşturulan eğriye göre direksiyon açısı üretilir. Aracın her hareketinde ileri bakma noktası değişeceği için her defasında yolun geometrisine göre yeni eğriler oluşturulur. Buna bağlı olarak direksiyon açısı da sürekli değişmiş olur. Şekil 3a' da Pure Pursuit yönteminin geometrik olarak gösterimi yer almaktadır.

Şekil 3a' da gösterilen $l_{d}$ mesafesi, aracın arka aks merkezinden referans alınarak belirlenir. $\mathrm{Bu}$ değer sabittir ve seçilen uzunluğa göre ileri bakma noktası $\left(x_{l a}, y_{l a}\right)$ belirlenir. Daha sonra bu iki noktadan geçen bir eğri oluşturulur. Bu eğri, anlık dönme noktasını merkez kabul eden bir çemberin parçasıdır. Oluşturulan bu çemberden yararlanılarak ve gerekli geometrik bağıntılar kullanılarak bir formülasyon oluşturulur ve buradan araç için gerekli direksiyon açısı $(\delta)$ üretilmiş olur. Pure Pursuit yönteminde direksiyon açısı aşağıdaki gibi hesaplanmaktadir. 


$$
\delta_{P P}=\tan ^{-1}\left(\frac{2 L \sin a}{l_{d}}\right)
$$

\subsection{Stanley Yöntemi}

Stanley yöntemi arka aksı referans olarak kullanan Pure Pursuit yönteminden farklı olarak, ön aksı referans olarak kabul eder. Bu yöntemde kontrolör hem yön hatasına hem de çapraz yol hatasına bakar. Çapraz yol hatası, aracın ön aksı ile yol üzerindeki en yakın nokta arasındaki dik mesafe olarak tanımlanır. Stanley yönteminde ileriye bakma davranışı yoktur. $\mathrm{Bu}$ nedenle yol geometrisinin değişimi öngörülemediği için keskin dönüş noktalarında çapraz yol hatası büyümektedir.

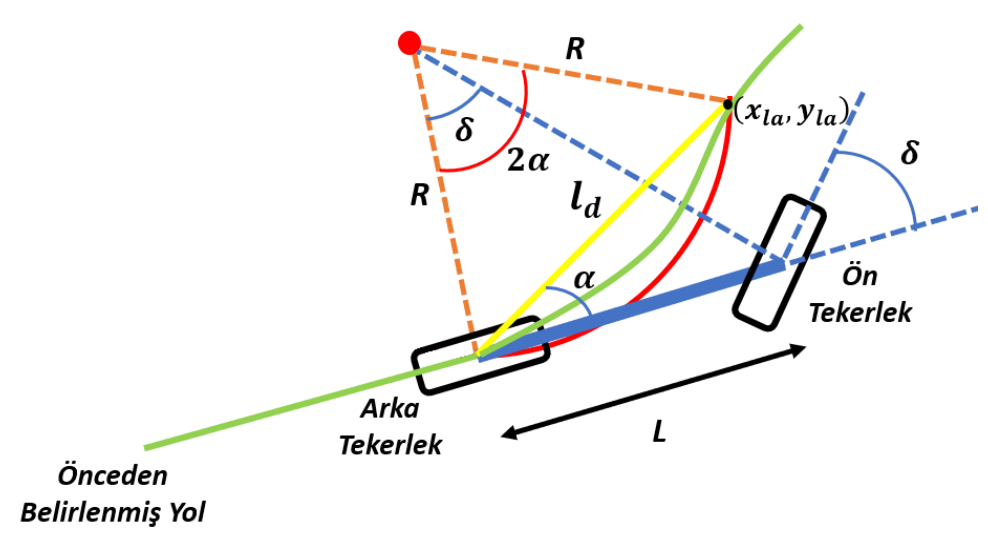

a)
Stanley metodu çapraz yol hatasını kullandığından dolayı bir PI kontrolör gibi davranıp hatayı daha hızlı telafi ederek yola diğer yöntemlerden daha çabuk yaklaşır ve oturur. Şekil 3b’ de Stanley metodunun geometrik temsili gösterilmektedir. Stanley yönteminde direksiyon açısı aşağıdaki gibi hesaplanmaktadır.

$$
\begin{gathered}
\delta=\tan ^{-1}\left(\frac{k \cdot e}{v}\right) \\
\delta_{S T}=\psi+\tan ^{-1}(k \cdot e / v), \quad \delta \in\left[\delta_{\text {min }}, \delta_{\text {max }}\right]
\end{gathered}
$$

Burada $e$ çapraz yol hatasıdır. $k$ ileri yol kazancı, $\psi$ yön hatası, $\delta_{S T}$ ise Stanley kontrolörün ürettiği direksiyon açısıdır.

Şekil 3. a) Pure Pursuit ve b) Stanley Yöntemlerinin Geometrik Olarak Gösterimi

\section{Bulanık Mantık Tabanlı Hibrit Kontrol Yöntemi}

Pure Pursuit ve Stanley yöntemlerin kendine göre avantaj ve dezavantajları bulunmaktadır. Pure Pursuit yönteminde ileri bakma davranışı olduğu için yapılacak manevra önceden tespit edilebilmektedir. Fakat bu davranış keskin dönüşlü yollarda yolu keserek takip etmesine ve takip hassasiyetinin oldukça azalmasına neden olmaktadır. Stanley yöntemi ise kesintisiz, sürekli yollarda daha iyi takip performansı ortaya koymakta ancak ileri bakma davranışı olmadığı için keskin dönüşlerde yüksek çapraz yol hatalarına neden olmaktadır. Bu çalışmada Pure Pursuit ve Stanley yöntemlerinin üstün yönlerinin bir araya getirildiği ve böylece yol takip performansının arttılmasının amaçlandığ 1 hibrit bir kontrol yöntemi sunulmaktadır. Önerilen

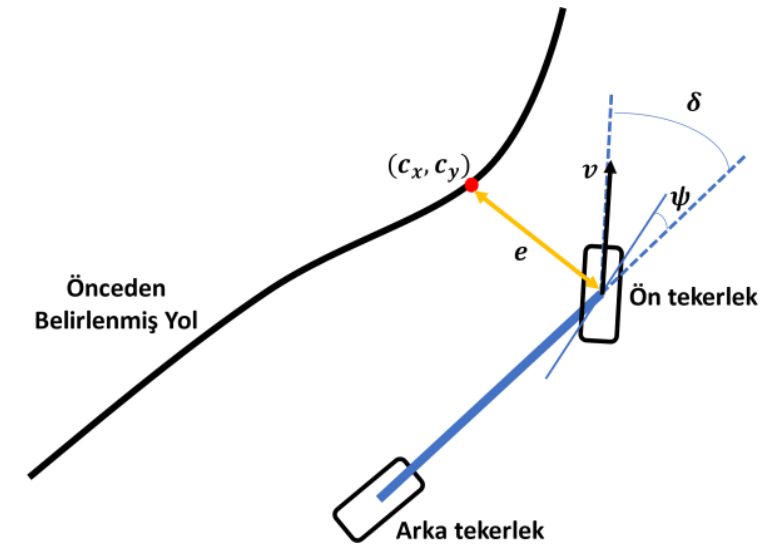

b) hibrit kontrol yönteminde Stanley ve Pure Pursuit yöntemleri ile elde edilen direksiyon açı değerleri ağırlıklandırılarak tek bir direksiyon açısı değeri hesaplanmaktadır. Ağırlıklandırma parametresi bir bulanık çıkarım mekanizması tarafından ileri bakma açısı değerlendirilerek dinamik olarak belirlenmektedir. Önerilen kontrol yönteminin blok diyagramı Şekil $7^{\prime}$ de gösterilmiştir. Yöntemde ağırlıklandırılmış direksiyon açısı aşağıdaki gibi hesaplanmaktadır.

$$
\delta_{\text {Hibrit }}=K_{1} \delta_{P P}+K_{2} \delta_{S T}
$$

Burada $\delta_{P P}$ ve $\delta_{S T}$ sirasiyla Pure Pursuit ve Stanley yöntemleri ile elde edilen direksiyon açılarıdır. $K_{1}=k$ ve $K_{2}=1-k$ olarak tanımlanmıştır. $k$ ise bulanık çıkarım mekanizmasının çıkışından elde edilen ağırlıklandırma değeridir.

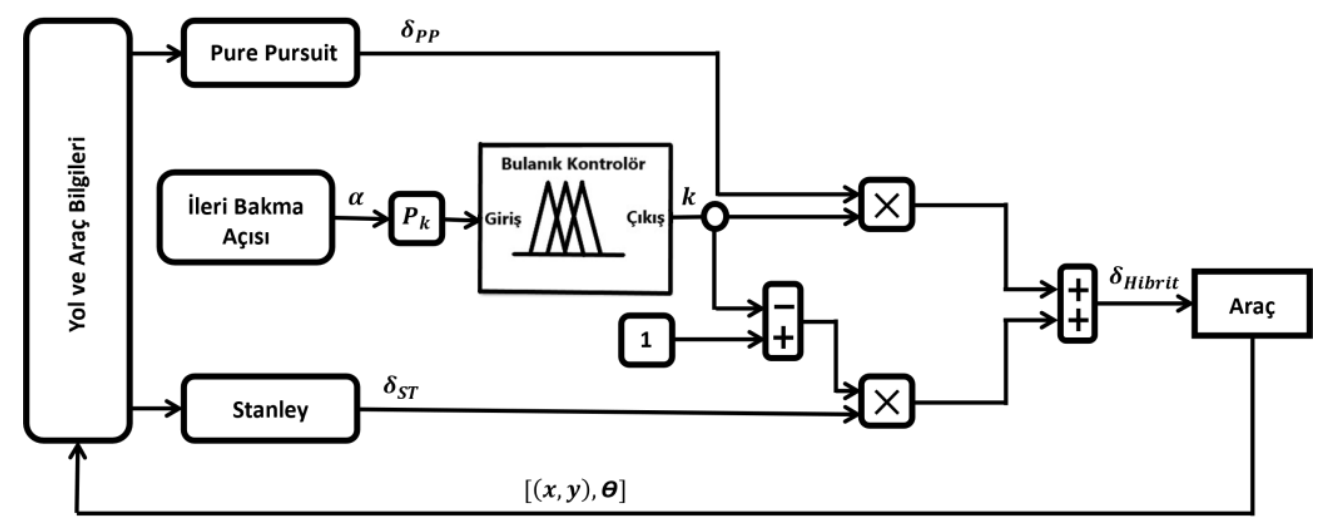

Şekil 7. Kontrolörün Şematik Yapısı 
Bulanık çıkarım mekanizması $\alpha$ ileri bakma açısına bağlı olarak uygun $k$ ağırlıklandırma değerini belirlemektedir. Açı değeri, Pure Pursuit yöntemindeki $l_{d}$ mesafesi referans alınarak hesaplanmıştır. $\mathrm{Bu}$ açı değerini $[0,1.5]$ değerleri arasında sınırlandırmak için bir $P_{k}$ ölçekleme çarpanı kullanılmıştır. Tanımlanan giriş ve çıkış üyelik fonksiyonları Şekil 8' de gösterilmiştir. Bulanık çıkarım mekanizmasının kural tabanı Tablo 1' de verilmiştir. Burada tanımlanan bulanık küme isimleri S sıfır, AK az küçük, K küçük, AB az büyük, B büyük, ÇB çok büyük, ST Stanley, AST az Stanley, APP az Pure Pursuit ve PP Pure Pursuit şeklindedir.

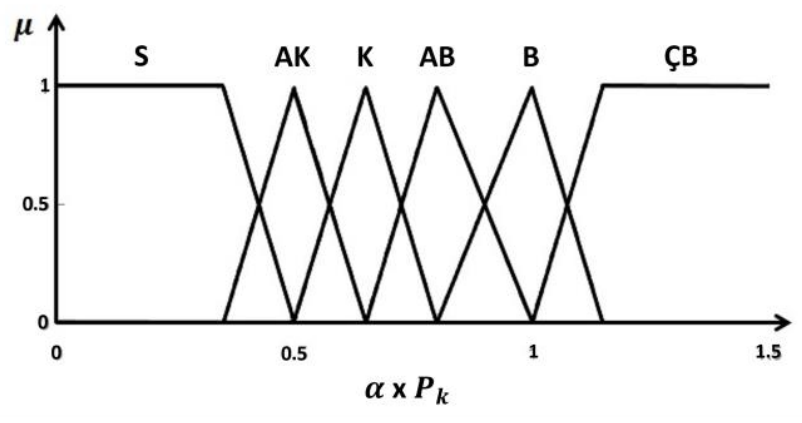

a)

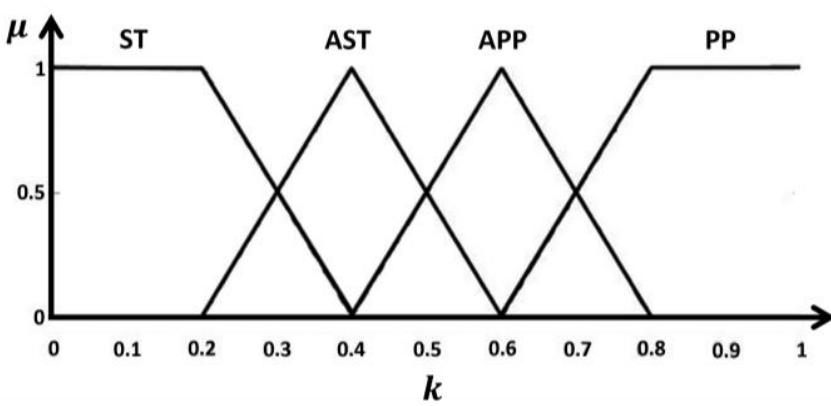

b)

Şekil 8. Giriş ve Çıkış Üyelik Fonksiyonları

Tablo 1. Kural Tabanı

\begin{tabular}{|c|c|c|c|c|c|c|}
\hline $\boldsymbol{\alpha}$ & $\mathrm{S}$ & $\mathrm{AK}$ & $\mathrm{K}$ & $\mathrm{AB}$ & $\mathrm{B}$ & ÇB \\
\hline $\boldsymbol{k}$ & $\mathrm{ST}$ & $\mathrm{ST}$ & $\mathrm{AST}$ & $\mathrm{APP}$ & $\mathrm{PP}$ & PP \\
\hline
\end{tabular}

\section{Benzetim Sonuçları}

Önerilen hibrit kontrol yönteminin performansını değerlendirmek için farklı yol senaryolarında benzetim çalışmaları gerçekleştirilmiş ve elde edilen sonuçlar Pure Pursuit, Stanley ve mevcut bir hibrit yol takip yöntemi (Cibooglu, Karapinar, ve Soylemez, 2017) ile elde edilen sonuçlarla karşılaştırılmıştır. Karşılaştırmalarda genel yumuşak dönüş ve keskin dönüş performanslarını değerlendirebilmek adına referans olarak dairesel yol ve 90 derece keskin dönüşlü yol tercih edilmiştir. Ayrıca araç hızı etkisini değerlendirebilmek için karşılaştırmalar 20, 50 ve $80 \mathrm{~km} / \mathrm{sa}$ olmak üzere üç ayrı sabit hızda gerçekleştirilmiştir.

Pure Pursuit kontrolör için ileri bakma mesafesi $d_{\text {ileri_bakma }}=d_{\text {sbt. }}+v * t_{\text {reak. }}$ olarak belirlenmiştir (Cibooglu,

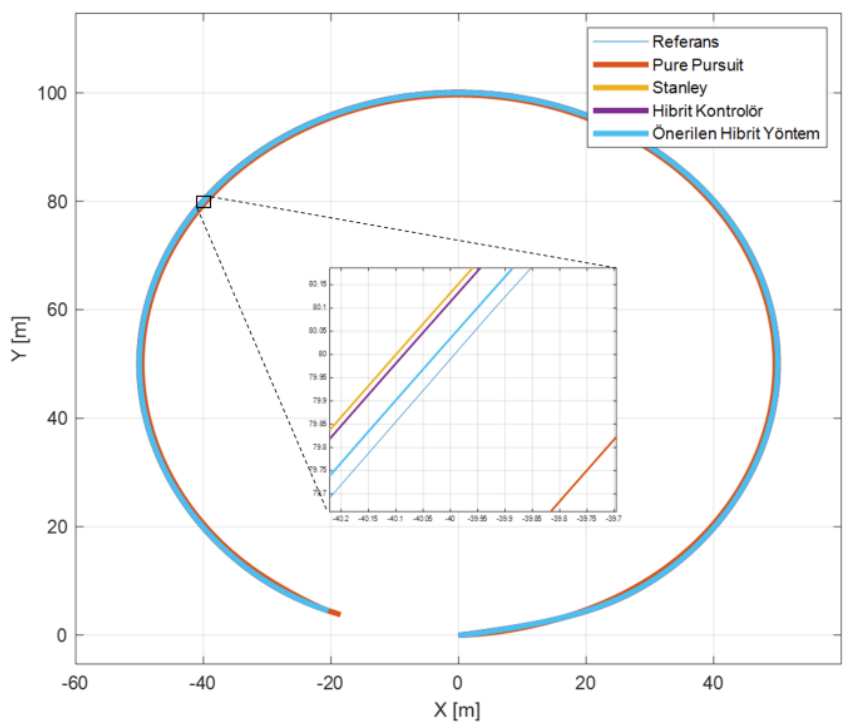

a)
Karapinar, ve Soylemez, 2017). Burada $d_{s b t}=4 \mathrm{~m}$ ve reaksiyon zamanı ise $t_{\text {reak. }}=0.7 \mathrm{~s}$ olarak seçilmiştir. Stanley kontrolör için ileri yol kazancı $k=2.5$ olarak seçilmiştir ve maksimum direksiyon açıları $[-15,15]$ aralığında sınırlandırılmıştır. Önerilen yöntemdeki bulanık çıkarım mekanizması ölçekleme çarpanı $P_{k}=1 / 40$ olarak seçilmiştir. Karşılaştırmalarda başarım ölçütü olarak hatanın karesinin integrali (HKI) ve mutlak hatanın integrali (MHI) ölçütleri kullanılmıştır. Bu ölçütlerde hata olarak çapraz yol hatası kullanılmıştır.

İki farklı yol referansında $50 \mathrm{~km} / \mathrm{sa}$ hız için elde edilen yol takip performansları Şekil 9' da gösterilmiştir. Tüm hızlar için elde edilmiş başarım ölçüt değerleri ise Tablo 2 ve Tablo 3' te verilmiştir.

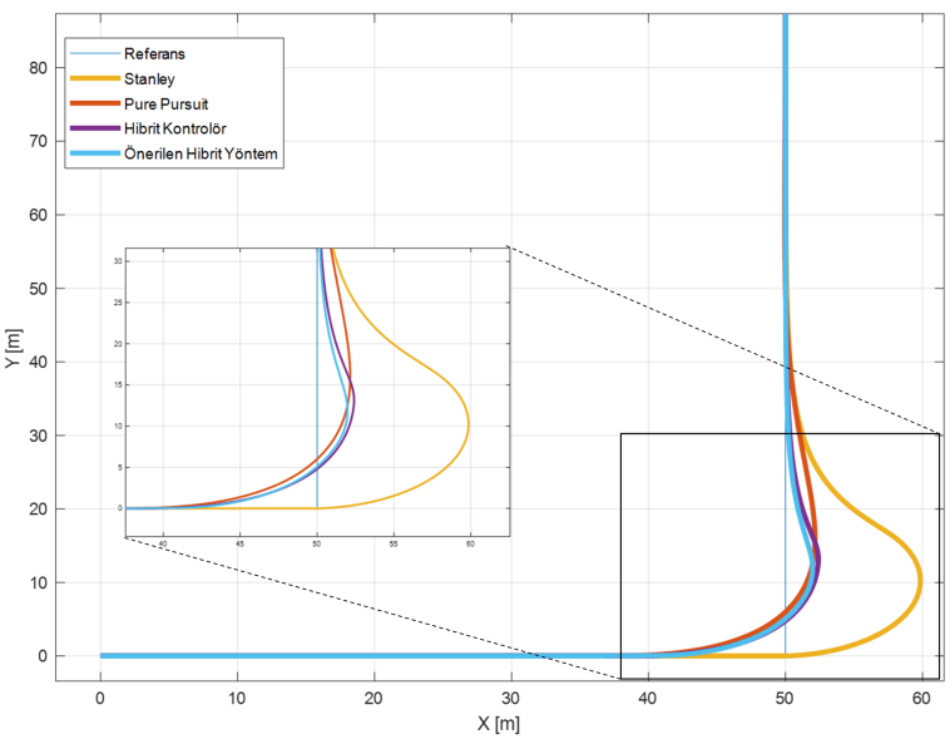

b)

Şekil 9. a) Dairesel Yol ve 90 Derece Keskin Dönüşlü Yol (50 km/sa) İçin Takip Performansı Sonuçları 
European Journal of Science and Technology

Tablo 2. Dairesel Yolda Hata Değerleri

\begin{tabular}{cccccc}
\hline \hline & & $\begin{array}{c}\text { Pure } \\
\text { Pursuit }\end{array}$ & Stanley & $\begin{array}{c}\text { Hibrit } \\
\text { Kontrolör }\end{array}$ & $\begin{array}{c}\text { Önerilen } \\
\text { Hibrit }\end{array}$ \\
\hline \multirow{2}{*}{$20 \mathrm{~km} / \mathrm{sa}$} & MHİ & 3,3768 & $\mathbf{2 , 5 7 0 1}$ & 2,6671 & 3,0875 \\
\cline { 2 - 6 } & HKİ & 0,9882 & $\mathbf{0 , 1 4 4 9}$ & 0,1537 & 0,1970 \\
\hline \multirow{2}{*}{$50 \mathrm{~km} / \mathrm{sa}$} & MHİ & 5,8096 & 3,2651 & 3,1225 & $\mathbf{2 , 3 4 7 8}$ \\
\cline { 2 - 6 } & HKİ & 1,4920 & 0,5177 & 0,4765 & $\mathbf{0 , 2 8 3 0}$ \\
\hline \multirow{2}{*}{$80 \mathrm{~km} / \mathrm{sa}$} & MHİ & 8,6590 & 4,1417 & 3,8621 & $\mathbf{3 , 4 9 9 6}$ \\
\cline { 2 - 6 } & HKİ & 1,6733 & 1,3221 & 1,1642 & $\mathbf{0 , 9 5 2 0}$ \\
\hline \hline
\end{tabular}

Tablo 2' den görüldüğü gibi dairesel yol referansı için düşük hızlarda $(20 \mathrm{~km} / \mathrm{sa})$ beklenildiği gibi en iyi performansı Stanley kontrolör göstermiştir. Fakat 50 ve $80 \mathrm{~km} / \mathrm{sa}$ gibi daha yüksek hızlarda açıkça görülmektedir ki önerilen yöntem diğer yöntemler arasında en iyi performansı sergilemektedir. Ani yol değişimlerinin olmadığ 1 bu tip yol referansında Stanley kontrolörün takip performansı Pure Pursuit kontrolörden her durumda daha iyidir. Mevcut hibrit kontrolör yüksek hızlarda hem Stanley hem de Pure Pursuit kontrolörden daha iyi performans göstermesine karşın önerilen hibrit kontrolörden daha düşük performans göstermiştir.

Tablo 3. 90 Derece Keskin Dönüşlü Yolda Hata Değerleri

\begin{tabular}{cccccc}
\hline \hline & & $\begin{array}{c}\text { Pure } \\
\text { Pursuit }\end{array}$ & Stanley & $\begin{array}{c}\text { Hibrit } \\
\text { Kontrolör }\end{array}$ & $\begin{array}{c}\text { Önerilen } \\
\text { Hibrit }\end{array}$ \\
\hline \multirow{2}{*}{$20 \mathrm{~km} / \mathrm{sa}$} & MHİ & 7,9556 & 15,6585 & 1,1196 & $\mathbf{0 , 9 5 2 1}$ \\
\cline { 2 - 6 } & HKI் & 7,4831 & 118,8089 & 0,6915 & $\mathbf{0 , 4 6 7 5}$ \\
\hline \multirow{2}{*}{$50 \mathrm{~km} / \mathrm{sa}$} & MHİ & 4,5116 & 16,6952 & 3,4635 & $\mathbf{2 , 8 0 3 3}$ \\
\cline { 2 - 6 } & HKI் & 17,0620 & 172,3866 & 6,3478 & $\mathbf{4 , 4 9 0 6}$ \\
\hline \multirow{2}{*}{$80 \mathrm{~km} / \mathrm{sa}$} & MHI் & 8,6713 & 30,1782 & 7,5274 & $\mathbf{5 , 9 5 1 4}$ \\
\cline { 2 - 6 } & HKI் & 32,5098 & 217,0714 & 31,4647 & $\mathbf{2 4 , 3 7 2 5}$ \\
\hline \hline
\end{tabular}

Elde edilen performanslar keskin dönüşlü yol referansı için değerlendirildiğinde, Tablo 3 ' ten görüldüğü gibi önerilen hibrit kontrol yönteminin diğer yöntemlere kıyasla daha iyi bir kontrol performansı sergilediği görülmektedir. Şekil 9b’ den görüldüğü gibi araç dönüş noktasına gelene kadar direksiyon açısı üretmediği için Stanley kontrolör ile elde edilen yanıtta referans yoldan fazla bir sapma olduğu görülmektedir. Öte yandan diğer yöntemlerde ileri bakma davranışı olduğu için daha erken direksiyon açısı üretildiği ve aracın daha erken yönlenmeye başladığı görülmektedir. Burada da bir önceki sonuçlara benzer şekilde mevcut hibrit kontrolör her durum için Pure Pursuit ve Stanley kontrolörlerden daha iyi bir performans sergilemiş fakat önerilen hibrit yöntemden daha düşük bir performans sergilemiştir. $\mathrm{Bu}$ durum hibrit kontrol yaklaşımının etkinliğini göstermektedir.

Sonuç olarak gerçekleştirilen yol takip performansı karşılaştırmaları ile en iyi performansı önerilen bulanık mantık tabanlı hibrit kontrolörün sağladığ 1 gösterilmiş ve önerilen yöntemin etkinliği kanıtlanmıştır.

\section{Sonuç}

$\mathrm{Bu}$ çalışmada otonom kara araçlarının yol takip performansını arttırmak için yaygın olarak kullanılan Stanley ve Pure Pursuit yol takip yöntemlerinin ağırlıklandırılarak bir arada kullanıldığı yeni bir hibrit yol takip yöntemi önerilmiştir. $\mathrm{Bu}$ hibrit yol takibi yönteminde dinamik bir ağırlıklandırma kullanılmış ve bu ağırlıklandırma parametresi değeri bir bulanık çıkarım mekanizması ile belirlenmiştir. Önerilen yöntemin etkinliği göstermek için benzetim çalışmaları yapılmış ve yöntemin performansı üç farklı yol takip yöntemi ile karşılaştırılmıştır. Elde edilen karşılaştırma sonuçları ile önerilen yöntemin keskin dönüşlü yollarda üç farkl 1 hız durumu için Pure Pursuit, Stanley ve mevcut hibrit kontrolörden daha iyi bir performans sergilediği gösterilmiştir. Dairesel yörünge referansında ise düşük hızlar dışında önerilen yöntemin diğer yöntemlere kıyasla daha üstün bir performans sergilediği görülmüştür. Önerilen yöntem karmaşık olmayan yapısı ve sağladığı performans artışı nedeniyle mevcut yöntemlere bir alternatif olarak otonom araçların yol takip uygulamalarında kullanılabilir.

Gelecek çalışmalarda önerilen yöntemde yol geometrisine bağlı olarak uyarlamalı hız kontrolü sağlayacak iyileştirmeler yapılması hedeflenmektedir.

\section{Kaynakça}

Amer, Noor Hafizah, Hairi Zamzuri, Khisbullah Hudha, and Zulkiffli Abdul Kadir. 2017. "Modelling and Control Strategies in Path Tracking Control for Autonomous Ground Vehicles: A Review of State of the Art and Challenges." Journal of Intelligent and Robotic Systems: Theory and Applications 86(2): 225-54.

Amidi, Omead, and Charles Thorpe. 1991. "Integrated Mobile Robot Control." Fibers' 91, Boston, MA 1388: 504-23. http://proceedings.spiedigitallibrary.org/proceeding.aspx?art icleid=954451.

Cibooglu, Mertcan, Umut Karapinar, and Mehmet Turan Soylemez. 2017. "Hybrid Controller Approach for an Autonomous Ground Vehicle Path Tracking Problem." 2017 25th Mediterranean Conference on Control and Automation, MED 2017 8: 583-88.

Guo, Hongyan et al. 2019. "Model Predictive Path Following Control for Autonomous Cars Considering a Measurable 
Disturbance: Implementation, Testing, and Verification.” Mechanical Systems and Signal Processing 118: 41-60. https://doi.org/10.1016/j.ymssp.2018.08.028.

Hoffmann, Gabriel M., Claire J. Tomlin, Michael Montemerlo, and Sebastian Thrun. 2007. "Autonomous Automobile Trajectory Tracking for Off-Road Driving: Controller Design, Experimental Validation and Racing." Proceedings of the American Control Conference: 2296-2301.

Jalali, Kiumars, Steve Lambert, and John McPhee. 2012. "Development of a Path-Following and a Speed Control Driver Model for an Electric Vehicle." SAE International Journal of Passenger Cars - Electronic and Electrical Systems 5(1): 100-113.

Park, Myung Wook, Sang Woo Lee, and Woo Yong Han. 2014. "Development of Lateral Control System for Autonomous Vehicle Based on Adaptive Pure Pursuit Algorithm." International Conference on Control, Automation and Systems (Iccas): 1443-47.

Park, Myungwook, Sangwoo Lee, and Wooyong Han. 2015. "Development of Steering Control System for Autonomous Vehicle Using Geometry-Based Path Tracking Algorithm."
ETRI Journal 37(3): 617-25.

Ping, Em Poh, and Sim Kok Swee. 2012. "Simulation and Experiment of Automatic Steering Control for Lane Keeping Manoeuvre." ICIAS 2012 - 2012 4th International Conference on Intelligent and Advanced Systems: A Conference of World Engineering, Science and Technology Congress (ESTCON) - Conference Proceedings 1: 105-10.

R. Craig Coulter. 1992. "Implementation of the Pure Pursuit Path Trahcing Algorithm." Camegie Mellon University.

Raffo, Guilherme V. et al. 2009. "A Predictive Controller for Autonomous Vehicle Path Tracking." IEEE Transactions on Intelligent Transportation Systems 10(1): 92-102.

Snider, Jarrod M. 2009. "Automatic Steering Methods for Autonomous Automobile Path Tracking." Work (February): $1-78$. http://www.ri.cmu.edu/pub_files/2009/2/Automatic_Steerin g_Methods_for_Autonomous_Automobile_Path_Tracking.p df.

Yu, Lingli et al. 2020. "Driverless Bus Path Tracking Based on Fuzzy Pure Pursuit Control with a Front Axle Reference." Applied Sciences (Switzerland) 10(1). 